\title{
Transition to work roles among youth in India
}

International Institute for Population Sciences (IIPS)

Population Council

Follow this and additional works at: https://knowledgecommons.popcouncil.org/departments_sbsr-pgy

Part of the Demography, Population, and Ecology Commons, Economic Policy Commons, Family, Life Course, and Society Commons, and the International Public Health Commons How does access to this work benefit you? Let us know!

\section{Recommended Citation}

International Institute for Population Sciences (IIPS) and Population Council. 2010. "Transition to work roles among youth in India," Youth in India: Situation and Needs Policy Brief no. 32. Mumbai: IIPS.

This Brief is brought to you for free and open access by the Population Council. 


\section{Transition to work roles among youth in India}

\begin{abstract}
"Achieving full and productive employment and decent work for all, including women and young people" is one of the targets articulated under the Millennium Development Goals and ratified by countries worldwide, including India. ${ }^{\text {a Also, }}$ reflecting India's commitment to meeting the employment needs of its citizens, new policy and programmatic initiatives have been launched in the country in recent years. For example, the Draft National Employment Policy aims to achieve "remunerative and decent employment for all women and men in the labour force"; $b$ and the recently approved National Policy on Skill Development (2009) aims to empower individuals, especially youth and women, through improved skills, knowledge and qualifications to gain access to employment in an increasingly competitive global market. ${ }^{c}$ It is important, in this context, to take stock of the extent to which youth in India are equipped to make a successful transition to work roles and the extent to which they are indeed making that transition. Specifically, are youth in the country transitioning into work roles at appropriate ages and with adequate skills? Are opportunities available that enable youth to overcome skill mismatches through vocational skills training? Are youth succeeding in finding productive employment and becoming integrated into the labour market?
\end{abstract}

Looking at the current employment situation of youth in India, this policy brief argues that significant investment in terms of appropriate policies and programmes are required to improve the employability of youth in the country and thereby enable them to find full and productive employment.

The study

Data are drawn from the Youth in India: Situation and Needs study, a sub-nationally representative study undertaken for the first time in India of key transitions experienced by young people in six states of India, namely, Andhra Pradesh,

Bihar, Jharkhand, Maharashtra, Rajasthan and Tamil Nadu. These states were purposively selected to represent the different geographic and socio-cultural regions within the country, and these six states together represent two-fifths of the country's population. The study included a representative survey of young people in both rural and urban settings. Respondents included unmarried women and men and married women aged 15-24 and, in view of the paucity of married men in these ages, married men aged 15-29.

The surveys in the six states were undertaken in a phased manner and took place between January 2006 and April 2008. A total of 50,848 married and unmarried young men and women were interviewed in the survey. These included 8,052 married young men, 11,522 unmarried young men, 13,912 married young women and 17,362 unmarried young women. This brief is based on data obtained from 14,281 men and 31,274 women aged 15-24.

The majority of youth were poorly equipped for employment

Findings from the Youth Study indicate that the majority of youth in the country were poorly equipped for employment for which there is a market demand. Most youth were neither adequately educated nor equipped with vocational skills.

\section{Few had completed secondary education}

Just two in five young men $(42 \%)$ and one in three young women (30\%) had completed secondary education, increasingly a prerequisite to participate in the labour market in the context of globalisation. ${ }^{\mathrm{de}}$ Indeed, one in twelve young men and one in four young women had never been to school at all in the country.

State-wise differences were notable; among young men, $44-52 \%$ of those from Maharashtra and the southern states of Andhra Pradesh and Tamil Nadu had completed 10 or more years of education, compared to $30-38 \%$ of those from the northern states of Bihar, Jharkhand and Rajasthan. Among young women, $36-48 \%$ of those in Maharashtra and the southern states, compared to $13-18 \%$ of those in the northern states, had done so.

\section{Few had acquired vocational skills}

A number of vocational training programmes are available to youth through government, non-government and private organisations. However, findings indicate that just one-fifth of young men $(21 \%)$ and a quarter of young women had ever attended a vocational training programme. Rural youth were considerably less likely than their

${ }^{a}$ United Nations Development Programme (UNDP). 2000. Millennium Development Goals. Accessed on 8 January, 2008 at $<$ http://www.un.org/millenniumgoals/goals.html $>$.

b Ministry of Labour and Employment. 2008. National Employment Policy. New Delhi: Ministry of Labour and Employment, Government of India. Accessed on 15 October, 2009 at <www.labour.nic.in>.

c Planning Commission. 2009. Coordinated Action on Skill Development. Accessed on 15 October, 2009 at $<$ http://planningcommission.gov.in/reports/ genrep/rep_csa.htm>.

${ }^{\mathrm{d}}$ United Nations. 2007. Goals and targets for monitoring the progress of youth in the global economy: Report of the Secretary-General. New York: United Nations.

e National Research Council and Institute of Medicine. 2005. Growing up Global: The Changing Transitions to Adulthood in Developing Countries. Washington, D.C.: The National Academies Press. 
urban counterparts to have received training ( $16 \%$ versus $32 \%$ among young men; $17 \%$ versus $43 \%$ among young women). Youth in Maharashtra and the southern states were more likely than their northern counterparts to have ever attended a vocational training programme $(22-31 \%$ versus $12-18 \%$ of young men; $30-33 \%$ versus $10-22 \%$ of young women).

The kind of training received varied by the sex of the respondent. Young women who had received vocational training had typically acquired traditional skills. For example, three in five (59\%) reported training in tailoring and one in four in handicrafts, painting or embroidery (24\%). Just one in four reported training in computer skills $(27 \%)$ and one in ten in English language or secretarial skills $(11 \%)$. Young men were far less likely to report training in traditional skills (just 5\% and $7 \%$ reported training in tailoring and crafts, for example). Indeed, among young men, leading training programmes reported included computer skills $(46 \%)$, auto mechanics or electrical work $(20 \%)$, driving (13\%) and English language or secretarial skills $(9 \%)$.

Findings also show that large proportions of youth- $56 \%$ of young men and $68 \%$ of young women-were interested in acquiring vocational skills. State-wise differences show that youth from Bihar, Jharkhand and Maharashtra (64-66\% and $71-82 \%$ among young men and women, respectively) were more likely than their counterparts in Rajasthan and the southern states (43-48\% and 53-63\% among young men and women, resp ectively) to report interest in attending vocational training programmes.

Skills in which youth wished to be trained virtually mirrored the pattern revealed above in terms of the types of vocational skills training received. While young men's preferences were focused on computer training, auto mechanics or electrical work, driving, and English language or secretarial skills, the majority of young women continued to opt for relatively traditional vocational skills, although substantial proportions-particularly those in urban areas-reported a preference for computer training and training in beauty parlour activities.

State-wise differences were apparent: larger proportions of youth in the southern states and Maharashtra (53-65\% of young men and 30-46\% of young women) than those in the northern states (36-49\% and $7-13 \%$, respectively) expressed a preference for training in new technologies, namely, computer skills.

Transition to work roles was not easy or successful for many

Work profiles suggest that the majority of young men $(61 \%$ of the unmarried and $97 \%$ of the married) and about two-fifths of young women ( $37 \%$ and $43 \%$, respectively) had been engaged in paid or unpaid work at some point in the 12 months preceding the interview. Findings, however, highlight that the transition to work roles is fraught with challenges.

\section{Sizeable numbers transitioned to work roles at young ages}

Despite the global recognition that entry into the labour market at young ages competes with young people's schooling opportunities and experiences directly or indirectly, and compromises their productive potential and health, ${ }^{\mathrm{f}}$ and despite significant policy and programme attention to the prevention of early entry into the labour market in India, ${ }^{\mathrm{g}}$ findings indicate that sizeable proportions of youth had transitioned to work roles at young ages. Indeed, over a quarter of young men and women $(28-29 \%)$ reported that they had initiated either paid or unpaid work as children or young adolescents, that is, before age 15. Rural youth were more likely than their urban counterparts to so report.

Young men in Bihar and Andhra Pradesh were more likely than those from the remaining states to have had initiated either paid or unpaid work before they were aged 15 (37\% versus 19-29\%). Among young women, while just one-sixth of those from Maharashtra and Tamil Nadu had initiated

Percentage of youth who had ever attended a vocational training programme and who were interested in participating in such programmes

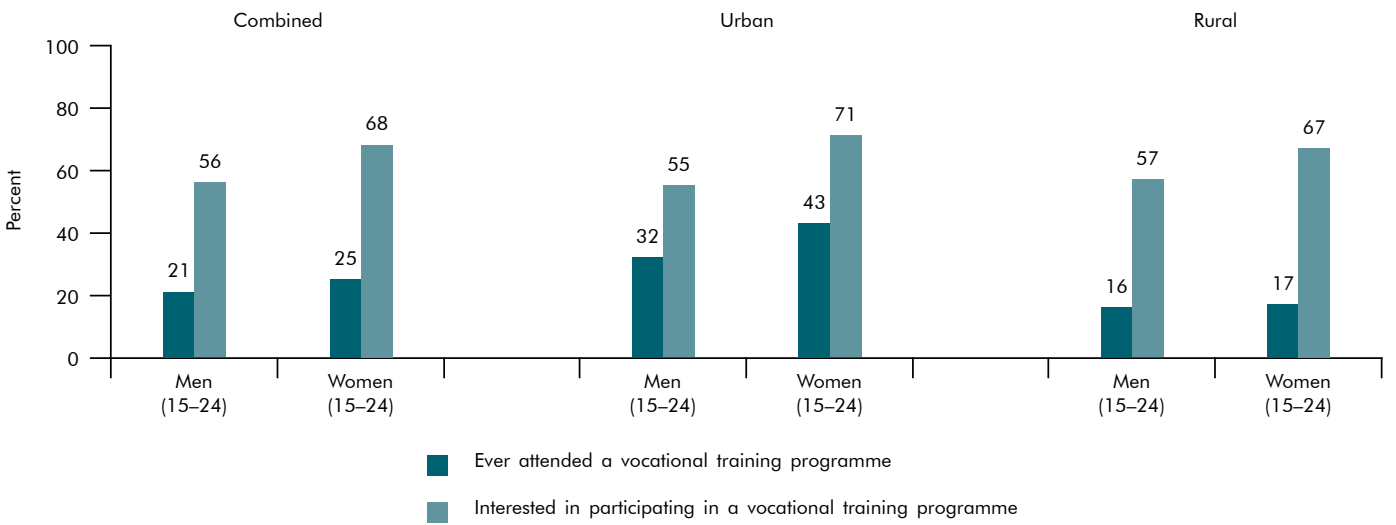

\footnotetext{
${ }^{\mathrm{f}}$ National Research Council and Institute of Medicine. 2005. Ibid.

g Ministry of Labour and Employment. 1986. The Child Labour (Prohibition and Regulation) Act 1986. New Delhi: Ministry of Labour and Employment, Government of India.
} 


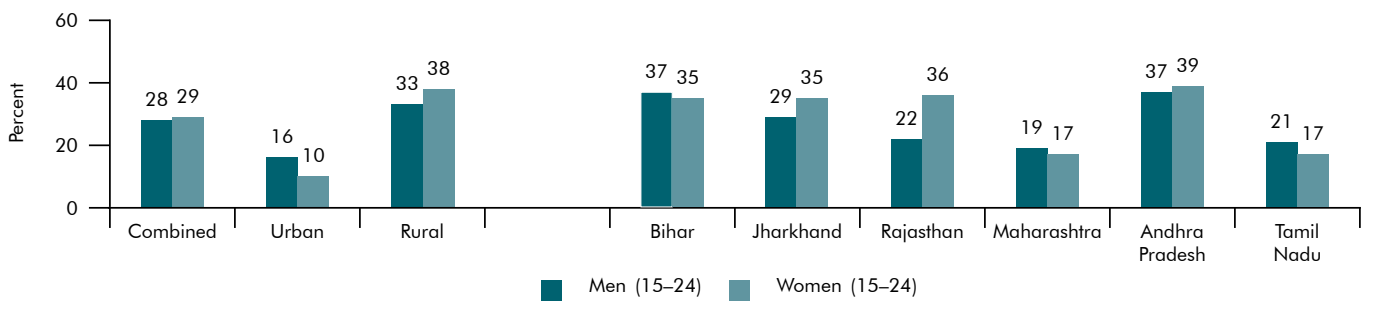

Unemployment rate among youth, according to selected characteristics

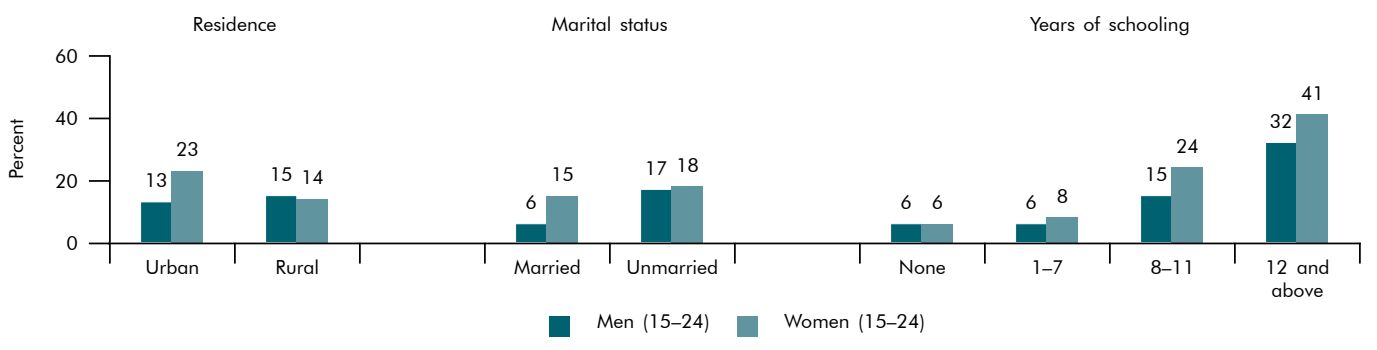

work in childhood or early adolescence, between one-third and two-fifths in the remaining states reported so.

\section{Youth were largely engaged in agricultural and unskilled non-agricultural activities}

The occupational profile of those engaged in remunerated work in the 12 months preceding the survey indicates that youth were working largely as agricultural and unskilled non-agricultural labourers- $50 \%$ of young men and $72 \%$ of young women. In contrast, skilled manual labour was reported by $31 \%$ of young men and $16 \%$ of young women. Just $7 \%$ of both young men and women were employed in administrative, executive, managerial or clerical occupations.

\section{Considerable proportions of young people were unemployed}

One in seven young men (14\%) and one in six young women $(16 \%)$ reported unemployment. ${ }^{1}$ While unemployment rates were similar among both urban and rural young men, the rate among urban young women was considerably higher than that observed among their rural counterparts. While unmarried young men were three times as likely as married young men to report unemployment, among young women, the married were about as likely as the unmarried to report unemployment.

Unemployment rate among youth, according to state

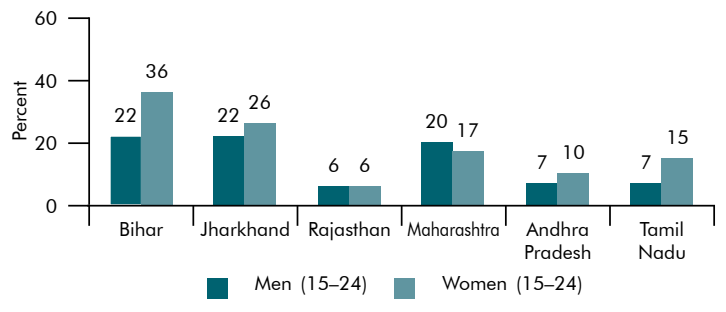

Notably, better educated youth were more likely to report unemployment than other youth, possibly because of the disconnect between youth skills and market needs. Among young men, for example, the unemployment rate increased from $6 \%$ among those with no formal education to $32 \%$ among those who had completed Class 12. Among young women, the rate increased from $6 \%$ among those with no formal education to $41 \%$ among those who had completed Class 12. These findings suggest that the paucity of opportunities limits the ability of even better qualified youth to obtain employment.

State-wise differences suggest that unemployment rates were higher among young men in Bihar, Jharkhand and Maharashtra than in the other states (20-22\% versus 6-7\%). Among young women, those from Bihar and Jharkhand reported unemployment rates higher than those reported in the remaining four states $(26-36 \%$ versus 6-17\%). Indeed, with 6\% unemployment, Rajasthan recorded the lowest unemployment rate among all the states.

\section{Many young women were neither in school nor working}

Findings suggest that large proportions of young men and women were either in school or working at the time of the interview and a few were both working and studying. However, findings also show

\section{Economic activity and schooling status among youth}

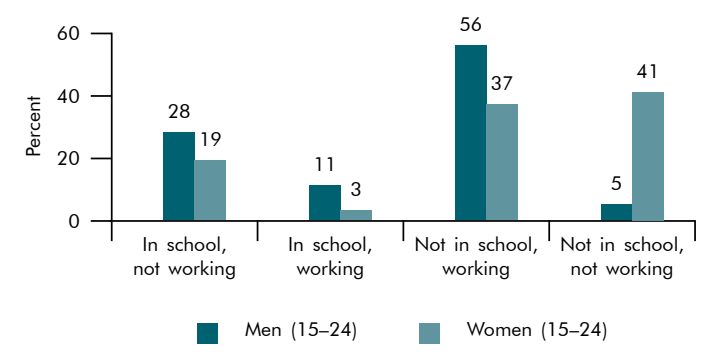

${ }^{1}$ To measure unemployment rates among respondents, the Youth Study assessed (a) whether youth had worked in the 12 months preceding the interview and if so, the number of months worked; and (b) whether youth were seeking work and if so, the number of months during which they had been searching for work. 
that the labour potential of young women was considerably under-utilised. For example, two-fifths of young women $(41 \%)$ were neither in school nor working, compared to just $5 \%$ of young men.

\section{Programme recommendations}

Findings indicate that several challenges remain in absorbing an increasingly youthful labour force and thereby harnessing the country's demographic dividend. A number of policies and programmes are needed to overcome these challenges.

\section{Increase investment in education}

Enhancing the employability of youth would depend to a considerable extent on improvements in young people's educational attainment. Multiple activities are needed to achieve improvement in educational attainment. Efforts must be made, for example, to address the economic pressures that may discourage parents from enrolling or retaining their children in school in favour of work. Conditional grants and targeted subsidies that encourage schooling, particularly school completion among disadvantaged groups also need to be considered. At the same time, activities are needed that are directed at parents that promote positive attitudes towards education and school completion, raise parents' aspirations for the education of their children and encourage greater parental involvement in their children's education.

Activities must also address school-level barriers, notably, poor infrastructure and quality of education. There is a need to incorporate livelihood skills building models within the school setting and provide opportunities for those in school to gain market-driven job skills that will expand the aspirations of youth regarding their education and careers. Moreover, investments in improving the quality of the schooling experience are needed that focus on providing better training of teachers and ensuring greater accountability among teachers.

Large numbers of youth have been left behind. Interventions are needed that give youth who missed the opportunity to obtain adequate formal education a second chance to acquire equivalency to formal education.

Several central and state government programmes, for example the Sarva Shiksha Abhiyan, the Rashtriya Madhyamik Shiksha Abhiyan and the Saakshar Bharat scheme are intended to encourage school enrolment and retention. What is needed is a strong commitment to ensuring that these programmes are effectively implemented and that they do indeed reach the most disadvantaged groups. Targeted efforts to achieve universal school enrolment and at least primary school completion need to be a high priority in the northern states, while concerted efforts to achieve universal secondary school completion are called for in Maharashtra and the southern states.
Strengthen efforts to prevent child labour

Findings of the Youth Study that over one in four young men and women had initiated work in childhood or in early adolescence (before age 15) reiterate the recommendation highlighted above regarding the need to provide conditional grants and targeted subsidies to disadvantaged groups, which would encourage parents to opt for schooling over work for their children. At the same time, it is important to vigorously enforce existing laws that prohibit child labour. Such efforts are particularly needed in Andhra Pradesh, Bihar, Jharkhand and Rajasthan.

\section{Enable youth to acquire vocational skills}

Findings have suggested that while vocational training programmes do exist, gaining access to these programmes is a significant obstacle for both young men and women; among those who obtained training, moreover, young women were particularly unlikely to obtain training in marketable skills. Formal mechanisms must be developed that provide opportunities to youth to acquire skills for which there is an established demand, and that link eligible youth to market opportunities. The proposed National Skills Development Initiative is a step in the right direction and it is important that this initiative is implemented without delay. At the same time, efforts are needed to promote self-employment and entrepreneurship through various livelihood schemes, for example, providing soft loans to youth to enable them to set up their own business enterprises.

\section{Ensure that existing programmes aimed at job creation reach youth}

While several programmes aimed at job creation are currently underway, findings indicate that considerable proportions of youth, particularly the educated, were unemployed at the time of interview and that the labour potential of young women remained largely under-utilised. Clearly, available programmes have failed to reach youth, notably young women, and are not equipped to encompass the needs of the educated. Efforts are needed to ensure that existing programmes aimed at job creations do indeed reach different groups of youth and that they target, in particular, young women. Also required are efforts to evaluate existing programmes aimed at job creation to assess their reach and impact in enabling young people to make a successful transition to work roles, upscale successful models and raise awareness among youth about their availability.

Finally, findings indicating considerable state-wise differences in unemployment rates and young people's participation in vocational training programmes call for state-specific interventions. Concerted efforts to improve the employability of youth and to enhance the reach of existing programmes aimed at job creation among youth are most urgently required in states like Bihar, Jharkhand and Rajasthan. At the same time, efforts to meet the large unmet need for vocational skills training are needed in all the six states. 